\title{
Influence of different light curing units on the bond strength of indirect resin composite restorations
}

\author{
Veridiana Camilotti(a) \\ Patricia Grau Grullón $n^{(a)}$ \\ Márcio José Mendonça ${ }^{(b)}$ \\ Paulo Henrique Perlatti D'Alpino(c) \\ João Carlos Gomes ${ }^{(d)}$ \\ (a) MSc Students in Operative Dentistry; \\ (c) Assistant Professor; (d) Professor and \\ Section Director - Department of \\ Restorative Dentistry, School of Dentistry, \\ State University of Ponta Grossa, PR, Brazil. \\ (b) Assistant Professor, Department of \\ Prosthodontics, School of Dentistry, Oeste \\ do Paraná University, PR, Brazil.
}

\begin{abstract}
The aim of this study was to evaluate the influence of different light sources on the bond strength of indirect resin composite restorations cemented with a dual-cure resin cement. The superficial dentin of human third molars was exposed and acid-etched and an adhesive system was applied (Single Bond 2). Four-mm-thick indirect resin composite restorations (Gradia) were fabricated and cemented using a dual-cure resin cement (Rely X). Four light sources were used to polymerize the cement: QTH - Optilux 401; LED1 - L.E.Demetron 1; LED2 - Optilight CL; and LED3 - Ultralume 5. The teeth were stored for $24 \mathrm{~h}$ and then sectioned, yielding stick-shaped specimens for each group with a bonded area of $1.0 \mathrm{~mm}^{2}$. The specimens were then tested in a universal testing machine, at a crosshead speed of $1 \mathrm{~mm} / \mathrm{min}$. Data were analyzed using ANOVA. Bond strength mean values were: QTH: $22.5( \pm 8.4)$; LED1: 22.7 ( \pm 9.4); LED2: $21.4( \pm 10.2$ ); and LED3: 27.3 ( \pm 13.8). No statistically significant difference was observed among the experimental groups. The bond strength values when the cement was polymerized using different LED lights were equivalent to the values when the QTH light was used. It can be concluded that the variety of light sources used in the present study did not influence the bond strength of indirect resin composite restorations cemented with a dual-cure resin cement.
\end{abstract}

Descriptors: Resin cements; Composite resins/standards.

\author{
Corresponding author: \\ Dr. João Carlos Gomes \\ Universidade Estadual de Ponta Grossa - PR \\ Departamento de Odontologia \\ Campus Uvaranas - Bloco M - $3^{\circ}$ Piso \\ Avenida General Carlos Cavalcanti, 4748 \\ Ponta Grossa - PR - Brazil \\ CEP: 84030-900 \\ E-mail: gomesjoaocarlos@uol.com.br
}

Received for publication on Aug 14, 2006

Accepted for publication on Jun 19, 2007 


\section{Introduction}

Advances in the field of light-curing have been remarkable, mainly after the development of blue light-emitting diodes (LED) lights for the photoactivation of resin composites. ${ }^{1}$ These new light curing devices are very compact, promise unlimited life, work at reduced voltage, do not require filters to limit the wavelength range and the light emitted is very specific for the camphorquinone/amine system. ${ }^{2}$ These devices are composed of solid-state LEDs that use junctions of doped semiconductors based on gallium nitride to directly emit light in the blue region of the spectrum, without excessive heating. ${ }^{3}$ These devices have improved and are now classified into generations. ${ }^{1}$

The first generation of LED lights was very limited ${ }^{4}$ due to a low power density (around $150 \mathrm{~mW} / \mathrm{cm}^{2}$ ), and had a worse performance than that of conventional quartz-tungsten-halogen $(\mathrm{QTH})$ lights. ${ }^{1}$ The second-generation LED lights provided superior results, delivering a greater power output. ${ }^{5}$ These light sources have a large area chip, which allows higher power operation; thus they are capable of achieving a polymerization degree similar to that produced by QTH lights with the same exposure time. ${ }^{2}$ An increase in temperature may occur; however it is dissipated quite quickly. The large area chip and a special thermal management, which prevents overheating, allow high power operation without thermal damage of the curing unit. These factors allow a higher light output and shorter exposure times. ${ }^{1,2,5}$ The spectral distribution of both first- and second-generation LED lights is narrower than that provided by QTH lights. ${ }^{6}$ However, these units are only able to effectively polymerize camphorquinone-amine-based composites. Also, LED light sources are less effective in light curing darker composite shades as these materials do not achieve a high degree of conversion when photoactivated with this type of units. ${ }^{4} \mathrm{An}$ increase in the power density and spectral distribution delivered would overcome the aforementioned drawbacks. ${ }^{4}$

A third generation of LED lights was then developed. ${ }^{1,6}$ In this case, there is an association with one or more low power density chips that emit light wavelengths in the violet color area of the electro- magnetic spectrum $(400 \mathrm{~nm}) .{ }^{1}$ The once narrow bandwidth and photo-initiator-specific nature of first- and second-generation lights was eliminated. The inclusion of short wave violet light may allow curing of alternate photoinitiators found in some specific types of resin-based restorative materials. Thus, LED lights can now be classified as "broadbanded" with respect to their output range. As the heating of these devices is directly correlated with their power density and the spectral distribution delivered, the LED elements must be cooled, or otherwise these components may burn out. ${ }^{1}$

The use of LED lights to polymerize direct composite restorations has been widely assessed in the dental literature. ${ }^{5,7}$ Therefore, the influence of LED devices on the microtensile bond strength of indirect composite restorations has, up to now, not been evaluated. The purpose of the present study is to investigate the influence of a variety of generations of blue light-emitting-diode lights to polymerize a dual-cure resin cement when an indirect resin composite is used to restore dental specimens. The null hypothesis to be tested is that there will be no difference in the bond strength values when laboratory processed resin restorations are cemented using a dual-cure resin cement. A selection of commercial LED lights was used to polymerize this restorative material and the results were compared to those of a conventional QTH light.

\section{Material and Methods}

Twenty sound human third molars were selected in the present study. Teeth were obtained and used in accordance with a protocol approved by the $\mathrm{Hu}$ man Ethical Committee (\#660/05, State University of Ponta Grossa, PR, Brasil). The teeth were stored in saline solution at $4{ }^{\circ} \mathrm{C}$ and used within 6 months after extraction. ${ }^{8}$ A flat dentin surface was exposed on each tooth after wet grinding the occlusal enamel on a \#180-grit silicon-carbide paper. ${ }^{9}$ In the event of pulp exposure, the specimen was discarded. The exposed dentin surfaces were further polished on a wet \#600-grit $\mathrm{SiC}$ paper for $60 \mathrm{~s}$ to standardize the smear layer. ${ }^{9}$ After specimen preparation, the indirect restorations were then fabricated directly on the surface of the exposed dentin area. In order to 
facilitate the posterior adaptation of the indirect restorations during the luting procedures, a groove was prepared in the mesial or distal aspect of the teeth using of a diamond bur $(3031 \mathrm{KG}$, Sorensen, Barueri, SP, Brazil). This area took part of the restored area and guided the cementation of the indirect restorations.

During restoration fabrication, the teeth were kept moist in saline solution at room temperature. A cylindrical-shaped restoration was constructed using a second generation laboratory processed resin (shade A2, Gradia, GC America, Alsip, IL, USA). The protocol to obtain the indirect restorations followed the application of the resin in four 1-mmthick consecutive increments. All increments were polymerized for $90 \mathrm{~s}$ in a xenon-stroboscopic device (Xenon Pulse Curing System, Kulzer, Belo Horizonte, MG, Brazil). The final composite increment was polymerized for $180 \mathrm{~s}$.

After restoration fabrication, the internal surfaces of the indirect restorations were sandblasted with $50 \mu \mathrm{m}$ aluminum oxide glass spheres (Sandblaster Micro Etcher, Syosset, NY, USA) for $10 \mathrm{~s}$. The dentin surfaces were then acid-etched $(37 \%$ phosphoric acid gel) for $15 \mathrm{~s}$, and then water-rinsed for $30 \mathrm{~s}$. Two coats of the adhesive system Adper Single Bond 2 (3M/ESPE, St. Paul, MN, USA) were applied following the manufacturer's directions, and then a blowing air was applied for solvent evaporation (5 s). ${ }^{10}$ The dentin surface was kept slightly shiny after adhesive application in all specimens. The light exposure time to polymerize the dentin-bonding agent was $10 \mathrm{~s}$ for all groups using a conventional quartz-tungsten-halogen light (Optilux 401 Demetron, Sybron, Newport Beach, CA, USA).
The dual-cure resin cement (3M/ESPE Rely X ARC, St. Paul, MN, USA) was proportioned according to the manufacturer's directions. ${ }^{11}$ Thereafter, the resin cement was applied to the internal surface of the indirect restorations and then placed according to their respective guides. Cement excesses were removed and then polymerized for $60 \mathrm{~s}$ in all tooth surfaces: buccal, lingual, mesial, distal and occlusal. Different light sources were used in the groups, as described in Table 1.

The power density was assessed using a conventional hand-held radiometer for the QTH light (Demetron Radiometer) and an L.E.D. Demetron Radiometer for the LED lights (Sybron, Newport Beach, CA, USA). All specimens were then stored for $24 \mathrm{~h}$ in a dark environment at room temperature $\left(37^{\circ} \mathrm{C}\right)$ and $100 \%$ relative humidity. After the storage time, the teeth were longitudinally sectioned in both the " $x$ " and " $y$ " directions across the bonded interface with a diamond saw mounted in a Labcut 1010 machine (Extec, Enfield, CT, USA), under water-cooling at $300 \mathrm{rpm}$. Bonded stick-shaped specimens were obtained with a cross-sectional area of $1.0\left( \pm 0.2 \mathrm{~mm}^{2}\right)$. The stick area was measured with a digital caliper after testing (Digimatic, Mitutoyo, Tokyo, Japan). Individual bonded sticks were positioned in a Universal Testing Machine (DL10000 EMIC, São José dos Pinhais, PR, Brazil) by means of cyanoacrylate-based cement and then subjected to tensile forces at a cross-head speed of $1.0 \mathrm{~mm} /$ min until failure. The results were recorded, and the debond stress values, converted into MPa. Data were submitted to one-way ANOVA and Tukey's post-hoc test, at a pre-set alpha of 0.05 . The distribution of failure mode of the tested specimen was

\begin{tabular}{|c|c|c|c|c|c|c|}
\hline \multirow{5}{*}{$\begin{array}{c}\text { Table } 1 \text { - Description } \\
\text { of the experimental } \\
\text { groups according to } \\
\text { light curing units. }\end{array}$} & \multirow[b]{2}{*}{ Groups } & \\
\hline & & Light curing unit & $\begin{array}{l}\text { Power density } \\
\left(\mathrm{mW} / \mathrm{cm}^{2}\right)\end{array}$ & $\begin{array}{l}\text { Light source } \\
\text { classification }\end{array}$ & $\begin{array}{c}\text { Light tip } \\
\text { diameter }(\mathrm{mm})\end{array}$ & $\begin{array}{c}\text { Refrigeration } \\
\text { system }\end{array}$ \\
\hline & QTH & $\begin{array}{l}\text { Optilux } 401 \text { Demetron } \\
\text { (Kerr) Lot\# } 40633009\end{array}$ & 550 & QTH & 13 & Yes \\
\hline & LED 1 & $\begin{array}{l}\text { L.E.Demetron } 1 \\
\text { (Kerr) Lot\# } 771006811\end{array}$ & 1,100 & $\begin{array}{l}\text { Second-generation } \\
\text { LED }\end{array}$ & 11 & Yes \\
\hline & LED3 & $\begin{array}{l}\text { Ultralume } 5 \\
\text { (Ultradent) Lot\# } 921552\end{array}$ & 1,100 & $\begin{array}{l}\text { Third-generation } \\
\text { LED }\end{array}$ & $10 \times 13$ & No \\
\hline
\end{tabular}


also evaluated at $40 \mathrm{X}$ magnification using a dissecting microscope (Lambda LEB-3, São Paulo, SP, Brasil) and classified as:

1. Cohesive failure (failure exclusively within the laboratory resin $[\mathrm{CR}]$ or dentin $[\mathrm{CD}])$;

2. Adhesive failure (fracture at the composite/dentin interface);

3. Adhesive/Mixed failure (failure at the composite/ dentin/resin cement interface including cohesive failures in the neighboring substrates).

\section{Results}

The microtensile bond strength values for the experimental groups are shown in Graph 1.

The highest bond strength mean value was seen when the LED3 light (Ultralume 5) was used $(27.3 \pm 13.8 \mathrm{MPa})$. The second-generation LED2 light (Optilight CL) presented the lowest bond strength mean value $(21.4 \pm 10.2 \mathrm{MPa})$. The control group (QTH light) bond strength mean value was similar to that obtained when the LED1 light was used (22.5 \pm 8.4 and $22.7 \pm 9.4 \mathrm{MPa}$, respectively). One-way ANOVA revealed that all the results were statistically equivalent $(\mathrm{p}>0.05)$.

The failure modes of the fractured specimens, after microtensile testing, are presented in Table 2. This table also shows the percentage of failure in the experimental groups. The great majority of failures observed were adhesive (from $88 \%$ to $100 \%$ ). The adhesive/mixed mode was the next most fre-

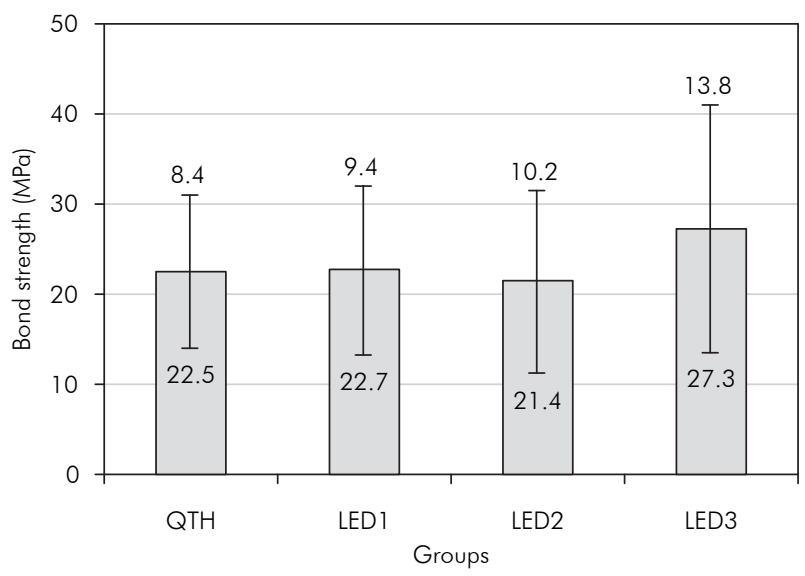

Graph 1 - Mean and standard deviation of bond strength values according to experimental groups. All values were statistically equivalent ( $p>0.05)$. quently observed failure mode (from $0 \%$ to $8 \%$ ). The cohesive failure mode in resin (CR) was observed the least in all the experimental groups $(0 \%$ to $4 \%)$. The cohesive failure mode in dentin (CD) was not detected in any of the microscopic analyses. The overall fracture mode results proved that the predominant failure mode was the adhesive fracture mode (94\%).

\section{Discussion}

The null hypothesis, that there would be no difference in bond strength when different lights were used to polymerize a dual-cure resin cement in indirect composite restorations, was validated. Statistical analysis revealed no significant difference among the groups $(\mathrm{p}>0.05)$. The reason to explain the values when different commercial light curing sources were used to polymerize the resin cement seems to be related neither to their power density output nor to their spectral irradiance. Equivalent bond strength values were observed when the QTH and the LED lights were used to polymerize the resin composite. The second-generation LED2 and the QTH light provided almost the same power density, whereas both the second- (LED1) and third-generation (LED3) LED lights showed an enormous difference in power density, but comparable dentin adhesion values. In addition, in terms of irradiance, the "broad-banded" QTH and LED3 lights provided similar bond strength values compared to the "narrow-banded" LED1 and LED2.

The evolving technology of curing light sources led to the advent of broad-banded LED lights in or-

Table 2 - Percentage of failure modes after microtensile bond strength testing for all experimental groups.

\begin{tabular}{l|r|c|c|c}
\hline \multicolumn{1}{c|}{ Groups } & A \% & AM \% & CD \% & CR \% \\
\hline QTH & 88 & 8 & 0 & 4 \\
\hline L.E.Demetron 1 (LED1) & 100 & 0 & 0 & 0 \\
\hline Optilight CL (LED2) & 100 & 0 & 0 & 0 \\
\hline Ultralume 5 (LED3) & 88 & 8 & 0 & 4 \\
\hline $\begin{array}{l}\text { Overall percentage of } \\
\text { failure mode }\end{array}$ & 94 & 4 & 0 & 2 \\
\hline
\end{tabular}

A: Adhesive failure; AM: Adhesive/Mixed failure; CD: Cohesive failure in dentin; CR: Cohesive failure in resin. 
der to allow the photoactivation of all types of resin-based materials, irrespective of the photoinitiator added. ${ }^{1}$ An increase in power density in conjunction with a wide spectral distribution seen in the thirdgeneration LED lights produces heating as a consequence. ${ }^{12,13}$ Despite the absence of significant differences, the heating produced by the third-generation LED light (LED3) might have led to an additional polymerization, which in turn, can explain why a higher bond strength mean value was observed when this light source was used.

It has been claimed that the resin cement polymerization should be optimized in order to resist deterioration of mechanical and chemical properties, among them strength, hardness, stiffness, and wear resistance. ${ }^{14}$ Studies have shown that dual-curing resin cements depend on photoactivation to achieve a high degree of conversion, and thus, a better performance. ${ }^{15}$ There is no agreement about the ideal power density needed to obtain optimal energy density, nor is there agreement about the irradiance of the light source, and the exposure time needed to cure resin cements sufficiently. ${ }^{16}$ These parameters are of particular interest since, in practice, they are under the control of the clinician. ${ }^{17,18}$ On the other hand, the results obtained in the present study do not corroborate these assumptions. In fact, these findings can be explained because a dual resin luting cement was used in the present study. The specimens were evaluated with the microtensile bond strength test after $24 \mathrm{~h}$, time after which the resin cement may have chemically completed its polymerization. ${ }^{19}$ Irrespective of the light source used, the results proved that the bond strength was significantly equivalent.

Dual-curing resin cements have been used for luting indirect esthetic restorations and most recently metal castings such as crowns and fixed partial dentures, as an alternative to zinc phosphate and glass ionomer cements. ${ }^{20}$ Some advantages of this type of resin cement are low solubility, adequate consistency and film thickness, superior mechanical properties, optimal bonding to dental structures and restoring materials by adhesive systems and reduced microleakage. ${ }^{21,22}$ Since the introduction of LED sources by Millis in 1995, several concerns about their efficiency for the light curing of resin-based materials have arisen. Regarding resin composites, several studies have demonstrated that LED devices are effective. ${ }^{23,24}$ On the other hand, as regards resin cements, few studies ${ }^{25-27}$ have only reported no significant differences using shear bond strength testing when QTH devices were compared to high-intensity LED light sources to polymerize a dual-cure resin cement through a 3-mm-thick ceramic restoration. It has been claimed that LED light units with a relatively low power output require a higher exposure time to perform as well as QTH lights. ${ }^{12}$

The findings observed in the present investigation suggest that, although high-intensity LED lights were also used to activate the resin cement, the polymerization of this restorative material was effective. The bond strength values seen in the experimental groups were equivalent. Clinically, the use of a light source when cementing an indirect restoration is important to allow immediate polymerization of the marginal cement, avoiding premature crown removal. Polymerization completion in the areas not reached by the curing light energy occurs through chemical reaction, which takes about $24 \mathrm{~h},{ }^{11}$ and it is essential for achieving adequate bond strength to the dental tissues. Also, despite the evolving technology, the conventional broad-banded QTH lights are effective for light curing of resin-based materials and can still be considered a control light for being able to polymerize all resin-based materials, irrespective of the photoinitiator.

\section{Conclusion}

Based on the results observed in the present study it can be concluded that the different light curing sources tested for light activation of the dual-cure resin cement did not influence the bond strength of a laboratory-processed composite to dentin tissue. Neither the power density, nor the spectral irradiance seems to interfere on the bond strength of the resin cement. 


\section{References}

1. Rueggeberg FA, Blalock JS, Callan RS. LED curing lights - what's new? Compend Contin Educ Dent. 2005;26(8):586-91.

2. Uhl A, Sigusch BW, Jandt KD. Second generation LEDs for the polymerization of oral biomaterials. Dent Mater. 2004;20(1):80-7.

3. Kurachi C, Tuboy AM, Magalhaes DV, Bagnato VS. Hardness evaluation of a dental composite polymerized with experimental LED-based devices. Dent Mater. 2001;17(4):309-15.

4. Caughman WF, Rueggeberg FA. Shedding new light on composite polymerization. Oper Dent. 2002;27(6):636-8.

5. Price RB, Felix CA, Andreou P. Evaluation of a second-generation LED curing light. J Can Dent Assoc. 2003;69(10):666.

6. Price RB, Felix CA, Andreou P. Evaluation of a dual peak third generation LED curing light. Compend Contin Educ Dent. 2005;26(5):331-8.

7. Park YJ, Chae KH, Rawls HR. Development of a new photoinitiation system for dental light-cure composite resins. Dent Mater. 1999;15(2):120-7.

8. Pashley DH, Carvalho RM, Sano H, Nakajima M, Yoshiyama M, Shono Y et al. The microtensile bond test: a review. J Adhes Dent. 1999;1(4):299-309.

9. Reis A, Loguercio AD, Azevedo CL, de Carvalho RM, da Julio Singer M, Grande RH. Moisture spectrum of demineralized dentin for adhesive systems with different solvent bases. J Adhes Dent. 2003;5(3):183-92.

10. Coelho Santos MJ, Navarro MF, Tam L, McComb D. The effect of dentin adhesive and cure mode on film thickness and microtensile bond strength to dentin in indirect restorations. Oper Dent. 2005;30(1):50-7.

11. 3M ESPE. Rely X ARC Adhesive resin cement system. Technical product profile. St. Paul: 3M Center; 1998.

12. Nomoto R, McCabe JF, Hirano S. Comparison of halogen, plasma and LED curing units. Oper Dent. 2004;29(3):287-94.

13. Trujillo M, Newman SM, Stansbury JW. Use of near-IR to monitor the influence of external heating on dental composite photopolymerization. Dent Mater. 2004;20(8):766-77.

14. Davidson-Kaban SS, Davidson CL, Feilzer AJ, de Gee AJ, Erdilek N. The effect of curing light variations on bulk curing and wall-to-wall quality of two types and various shades of resin composites. Dent Mater. 1997;13(6):344-52.

15. Papazoglou E, Rahiotis C, Kakaboura A, Loukidis M. Curing efficiency of a photo- and dual-cured resin cement polymer- ized through 2 ceramics and a resin composite. Int J Prosthodont. 2006;19(1):34-6.

16. Ernst CP. Clinical aspects of photopolymerization. In: Scientific insights into dental ceramics and photopolymer networks; 2004. Geneva: Academy of Dental Materials 2004. p. 105 17.

17. Daronch M, Rueggeberg F, de Goes MF. Monomer conversion of pre-heated composite. J Dent Res. 2005;85(7):663-7.

18. Halvorson RH, Erickson RL, Davidson CL. Energy dependent polymerization of resin-based composite. Dent Mater. 2002;18(6):463-9.

19. Venhoven BA, de Gee AJ, Davidson CL. Light initiation of dental resins: dynamics of the polymerization. Biomaterials. 1996;17(24):2313-8.

20. Fonseca RG, Santos JG, Adabo GL. Influence of activation modes on diametral tensile strength of dual-curing resin cements. Braz Oral Res. 2005;19(4):267-71.

21. Van Meerbeek B, Inokoshi S, Davidson CL, De Gee AJ, Lambrechts P, Braem M et al. Dual cure luting composites - Part II: Clinically related properties. J Oral Rehabil. 1994;21(1):5766.

22. Yoshida K, Tanagawa M, Atsuta M. In vitro solubility of three types of resin and conventional luting cements. J Oral Rehabil. 1998;25(4):285-91.

23. Bennett AW, Watts DC. Performance of two blue light-emitting-diode dental light curing units with distance and irradiation-time. Dent Mater. 2004;20(1):72-9.

24. Teshima W, Nomura Y, Tanaka N, Urabe H, Okazaki M, Nahara Y. ESR study of camphorquinone/amine photoinitiator systems using blue light-emitting diodes. Biomaterials. 2003;24(12):2097-103.

25. Foxton RM, Pereira PN, Nakajima M, Tagami J, Miura H. Durability of the dual-cure resin cement/ceramic bond with different curing strategies. J Adhes Dent. 2002;4(1):49-59.

26. Nalcaci A, Kucukesmen C, Uludag B. Effect of high-powered LED polymerization on the shear bond strength of a light-polymerized resin luting agent to ceramic and dentin. J Prosthet Dent. 2005;94(2):140-5.

27. Tashiro H, Inai N, Nikaido T, Tagami J. Effects of light intensity through resin inlays on the bond strength of dual-cured resin cement. J Adhes Dent. 2004;6(3):233-8. 